\title{
Uncertainty Assessment for Very High Temperature Thermal Diffusivity Measurements on Molybdenum, Tungsten and Isotropic Graphite
}

\author{
Bruno Hay $^{1}$ D . Olivier Beaumont ${ }^{1}$ - Guillaume Failleau ${ }^{1} \cdot$ Nolwenn Fleurence $^{1}$. \\ Marc Grelard ${ }^{1}$ - Refat Razouk ${ }^{1}$ - Guillaume Davée ${ }^{1}$ · Jacques Hameury ${ }^{1}$
}

Received: 11 September 2021 / Accepted: 30 September 2021 / Published online: 17 October 2021

(c) The Author(s) 2021

\begin{abstract}
The French National Metrology Institute LNE has improved its homemade laser flash apparatus in order to perform accurate and reliable measurements of thermal diffusivity of homogeneous solid materials at very high temperature. The inductive furnace and the associated infrared (IR) detection systems have been modified and a specific procedure for the in situ calibration of the used radiation thermometers has been developed. This new configuration of the LNE's diffusivimeter has been then applied for measuring the thermal diffusivity of molybdenum up to $2200{ }^{\circ} \mathrm{C}$, tungsten up to $2400{ }^{\circ} \mathrm{C}$ and isotropic graphite up to $3000{ }^{\circ} \mathrm{C}$. Uncertainties associated with these high temperature thermal diffusivity measurements have been assessed for the first time according to the principles of the "Guide to the Expression of Uncertainty in Measurement" (GUM). Detailed uncertainty budgets are here presented in the case of the isotropic graphite for measurements performed at $1000{ }^{\circ} \mathrm{C}$, $2000{ }^{\circ} \mathrm{C}$ and $3000{ }^{\circ} \mathrm{C}$. The relative expanded uncertainty (coverage factor $k=2$ ) of the thermal diffusivity measurement is estimated to be between $3 \%$ and $5 \%$ in the whole temperature range for the three investigated refractory materials.
\end{abstract}

Keywords High temperature $\cdot$ Isotropic graphite $\cdot$ Molybdenum $\cdot$ Thermal diffusivity $\cdot$ Tungsten $\cdot$ Uncertainty

\section{Introduction}

Nuclear energy and space industries, which operate facilities and equipment at temperatures above $1500{ }^{\circ} \mathrm{C}$, have used for a long time high temperature resistant materials for their specific applications $[1,2]$. Thanks to emerging developments

Bruno Hay

bruno.hay@lne.fr

1 Laboratoire National de Métrologie et d'Essais, Laboratoire Commun de Métrologie (LNE-

CNAM), 29 avenue Roger Hennequin, 78197 Trappes, France 
in material science, these industries develop new refractory materials able to work at higher temperatures in order to optimise their processes and to expand safety margins and the efficiency of particular technologies.

In nuclear applications, silicon carbide-based composite materials are seen today as a promising alternative to the current zirconium-based alloys (commonly used for manufacturing fuel claddings) for the use of accident tolerant fuel as their oxidation temperature is far higher than that of zirconium-based alloys (approximately $2000{ }^{\circ} \mathrm{C}$ versus $1200{ }^{\circ} \mathrm{C}$ ) [3, 4]. In space applications, space modules and vehicles $[5,7]$ need thermal shields for their exploratory missions or during re-entry in atmosphere in order to resist to temperatures that can be higher than $2500{ }^{\circ} \mathrm{C}$.

In the examples above, the knowledge of the thermal diffusivity of the used advanced materials as a function of temperature is crucial for predicting their behaviour in real conditions. In addition, accurate data of thermal diffusivity are also needed for the thermal modelling of abnormal and accident scenarios, during which materials would be exposed to ultra-high temperatures.

Although some dedicated facilities exist in the concerned industries for measuring thermal diffusivity, it is not possible to ensure the reliability of the measured data above $1500{ }^{\circ} \mathrm{C}$ and their traceability to the International System of Units (SI), due to a lack of appropriate standard reference materials and reference facilities.

To address these metrological needs, LNE has improved the measurement capabilities of its reference apparatus based on the laser flash method to measure thermal diffusivity of homogeneous solid materials up to $3000{ }^{\circ} \mathrm{C}$ with a target expanded uncertainty of few percent. This work has been performed within the framework of the European joint research project "Hi-TRACE-Industrial process optimisation through improved metrology of thermophysical properties" [8]. The overall objective of the Hi-TRACE project, coordinated by LNE, is to establish a European metrological infrastructure composed of reference facilities in order to provide industries with traceable thermophysical properties measurements (thermal diffusivity, specific heat and emissivity) at very high temperature.

Several papers dealing with uncertainty analysis associated with thermal diffusivity measurements performed using the laser flash method have been published during the last two decades. They present the identification and quantification of influencing parameters and sources of measurement errors [9, 10], the establishment of detailed uncertainty budgets $[11,12]$ according to the ISO/BIPM Guide to the expression of uncertainty in measurement [13], or the development of alternative approaches (e.g., Bayesian or multi-convolutional approaches) to evaluate the uncertainty on thermal diffusivity measurements [14-16]. All these published works are limited to measurements performed from room temperature to $1000{ }^{\circ} \mathrm{C}$ at maximum, and sometimes do not take into account the contribution of some significant uncertainty factors (spatially non-uniform heating, non-linearity of the infrared detector output with respect to temperature, variation of the specimen thickness due to the thermal expansion of the tested material...).

After a brief description of the metrological facility and method that have been implemented at LNE for measuring the thermal diffusivity up to $3000{ }^{\circ} \mathrm{C}$, this paper presents the results obtained on isotropic graphite, tungsten and molybdenum 
specimens, and for the first time gives detail of uncertainty budgets associated with very high temperature thermal diffusivity measurements.

\section{Method of Measurement}

LNE has performed for many years thermal diffusivity measurements of homogeneous solid materials up to $2000{ }^{\circ} \mathrm{C}$ in inert or vacuum environments by using a homemade facility [17] based on the well-known principle of the rear face laser flash method [18]. In this method, a cylindrical specimen is heated on its front face by a short energy pulse, and the induced transient temperature rise is measured on its back face versus time. The thermal diffusivity is determined with an estimation procedure based on minimizing the difference between the experimental temperature-time curve (thermogram) and the same curve given by a theoretical model of the transient heat conduction through the specimen. In the case of a bulk homogeneous material, the thermal diffusivity is estimated by LNE according to the partial time moments method [19]. This identification method was used by LNE for example in the certification process of Pyroceram 9606 as BCR-724 reference material [20] and in the first international inter-laboratory comparison on thermal diffusivity measurements organized by the Bureau International des Poids et Mesures (BIPM) $[21,22]$.

\subsection{Description of the Apparatus}

In its former configuration, the laser flash apparatus of LNE was equipped with two furnaces, a resistive furnace operating from room temperature to $800{ }^{\circ} \mathrm{C}$ and an inductive one for the measurements performed from $700{ }^{\circ} \mathrm{C}$ to $2000{ }^{\circ} \mathrm{C}$. The inductive furnace has been recently improved to enable the thermal diffusivity measurement of solid homogeneous materials up to $3000{ }^{\circ} \mathrm{C}$.

A schematic representation of this facility is shown in Fig. 1a. The specimen (disk of $10 \mathrm{~mm}$ in diameter and $1 \mathrm{~mm}$ to $4 \mathrm{~mm}$ thick) is maintained at a constant temperature in the inductive furnace composed by an airtight enclosure water cooled in the centre of which an inductive coil and a movable susceptor are placed on a vertical axis.

The inductive coil is a copper solenoid also cooled by circulation of water and connected to a $50 \mathrm{~kW}$ high frequency generator (100 kHz to $400 \mathrm{kHz}$ ). Its geometry has been optimised (reduction of the number of turns from 5 to 4 to increase the distance between each turn and coating of the coil with a ceramic deposit) in order to avoid the appearance of sparks between the susceptor and the coil as well as sparks between the turns themselves that can damage the susceptor and disturb the measurements. Figure $1 \mathrm{~b}$ presents a picture of the new copper induction coil with the ceramic coating.

The susceptor is a hollow cylinder having a shoulder machined at mid-height to maintain the specimen. The Foucault currents induced in the susceptor generate heat by Joule heating, the specimen located inside being then heated primarily by 


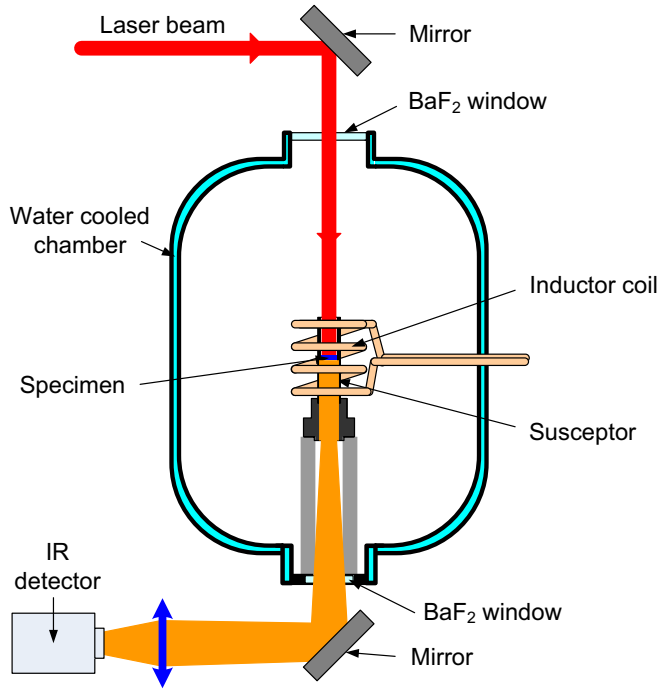

(a) Schematic diagram of the diffusivimeter of LNE

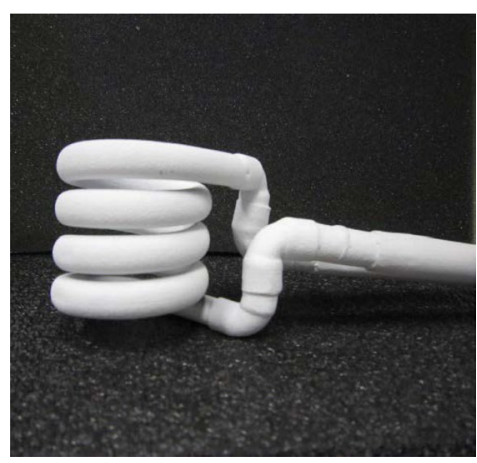

(b) Inductive coil

Fig. $1 \mathrm{LNE}$ facility for the thermal diffusivity measurement of solid materials up to $3000{ }^{\circ} \mathrm{C}$

radiative transfer. Depending on the temperature range and the material of the specimen, a thin washer made of molybdenum or tungsten is put between the specimen and the graphite susceptor in order to avoid any direct contact between them with the objective to limit chemical interactions at high temperature. The geometry of the susceptor has been modified and the diameter of its support has been reduced in order to limit conduction heat losses. The cooling loop of the inductive coil and of the enclosure has been improved in order to both increase the cooling efficiency and to reduce the temperature variations of the enclosure wall from $29^{\circ} \mathrm{C} \pm 2{ }^{\circ} \mathrm{C}$ to $29{ }^{\circ} \mathrm{C} \pm 0.3{ }^{\circ} \mathrm{C}$.

Two power supplies have been implemented in the high frequency generator of the inductive furnace in order to optimize the temperature resolution depending on the level of temperature: a $25 \mathrm{~kW}$ configuration enabling to reach $2800{ }^{\circ} \mathrm{C}$ with a temperature resolution of $12{ }^{\circ} \mathrm{C}$ at $1000{ }^{\circ} \mathrm{C}$ and $1{ }^{\circ} \mathrm{C}$ at $2800{ }^{\circ} \mathrm{C}$, and a $50 \mathrm{~kW}$ configuration for higher temperatures with temperature resolution of $25^{\circ} \mathrm{C}$ at $1000{ }^{\circ} \mathrm{C}$ and $2{ }^{\circ} \mathrm{C}$ at $3000{ }^{\circ} \mathrm{C}$. A filter has been put at the output of the $\mathrm{HF}$ generator to reduce the high frequency electromagnetic interferences $(>250 \mathrm{kHz})$. These modifications enable to increase the signal to noise ratio and therefore to obtain exploitable thermograms up to $3000{ }^{\circ} \mathrm{C}$. The furnace is equipped with two $\mathrm{BaF}_{2}$ windows, which are transparent (transmission higher than $90 \%$ from $0.25 \mu \mathrm{m}$ up to $10 \mu \mathrm{m}$ ) to the laser wavelength and to the wavelength ranges of the IR detectors.

The temperature of the specimen is measured during heating of the furnace as well as when temperature is stabilized at target temperature with one of the two infrared bi-chromatic radiation thermometers $(0.90 \mu \mathrm{m}$ and $1.05 \mu \mathrm{m})$ operating in the temperature ranges $\left[700{ }^{\circ} \mathrm{C}\right.$ to $\left.1800{ }^{\circ} \mathrm{C}\right]$ or $\left[1000{ }^{\circ} \mathrm{C}\right.$ to $\left.3000^{\circ}\right]$. They are installed on a linear stage enabling to put one or the other opposite the $90^{\circ}$ 
flat mirror attached below the movable susceptor. These radiation thermometers can be subjected to drift along time and need thus to be periodically calibrated to ensure trueness of temperature measurements. A specific protocol, based on the use of metal-carbon eutectic high temperature fixed points positioned in the furnace at the location of the specimens, has been therefore developed at LNE in order to enable the in situ calibration of the radiation thermometers [23]. The eutectic fixed points are palladium-carbon $\left(1492{ }^{\circ} \mathrm{C}\right)$, platinum-carbon $\left(1738{ }^{\circ} \mathrm{C}\right)$ and iridium-carbon $\left(2290^{\circ} \mathrm{C}\right)$.

The short thermal excitation (duration around $450 \mu \mathrm{s}$ ) is generated by a $\mathrm{Nd}$ :phosphate glass laser at $1054 \mathrm{~nm}$ wavelength, whose beam is formed by a set of lenses, mirrors and stops so that its diameter is about $10 \mathrm{~mm}$ on the front face of the specimen. A photodiode is used to measure the duration, the temporal profil of the pulse, and the time origin that corresponds to the time when the laser beam irradiates the specimen. The induced transient temperature rise of the specimen rear face is measured optically with an infrared detector $(\mathrm{HgCdTe}, \mathrm{InGaAs}$ and $\mathrm{Si}$ depending on the temperature range). An optical system made of lenses is associated to each IR detector in order to collect the infrared radiation emitted by the specimen rear face.

\subsection{Estimation Process of Thermal Diffusivity}

The thermal diffusivity is determined by identification of the experimental thermogram with a theoretical model, which is in the classical case of a homogeneous material a two-parameter unidirectional model depending on the thermal diffusivity $a$ and the dimensionless Biot number $B i$ (which represents the thermal exchanges between the specimen and its surrounding). This analytical model is obtained by solving the heat conduction equation for the case of a homogeneous, isotropic and opaque specimen assuming that the model is linear (thermophysical properties are considered independent of the temperature), the heat losses between the sample and its surrounding are characterized by a uniform and constant in time heat exchange coefficient, the laser pulse is spatially uniform and can be considered as a Dirac pulse.

In the partial time moments method [19], the thermal diffusivity is estimated from the partial time moments of order 0 and -1 determined for the experimental and theoretical thermograms $f(t)$ normalized by their maxima (an example of experimental thermogram is given in Fig. 2).

$$
f(t)=\left(U(t)-U_{0}\right) /\left(U_{\max }-U_{0}\right)
$$

where $U(t), U_{0}$ and $U_{\text {max }}$ are, respectively, the output voltage of the infrared detector as a function of time $t$, the minimum and the maximum of the thermogram.

The experimental $\left(m_{0}\right.$ and $\left.m_{-1}\right)$ and theoretical $\left(m_{0}^{*}\right.$ and $\left.m_{-1}^{*}\right)$ partial time moments are written in a general way as follows, where $t_{0.1}$ and $t_{0.8}$ correspond to the times needed to the back face of the specimen to reach, respectively, $10 \%$ and $80 \%$ of the maximum amplitude of the thermogram: 


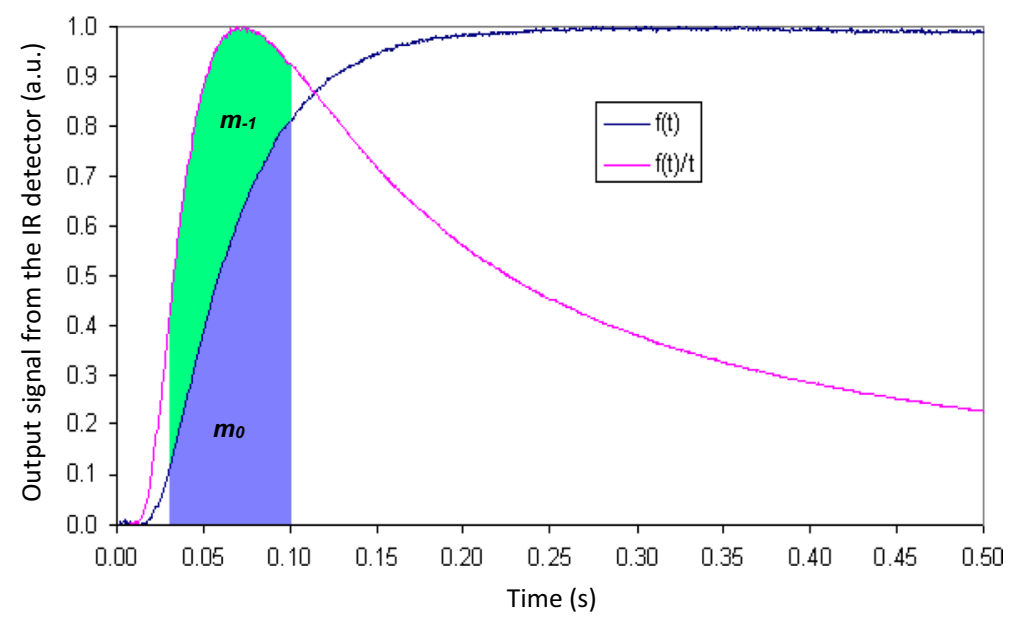

Fig. 2 Example of experimental thermogram

$$
m_{0}=\int_{t_{0.1}}^{t_{0.8}} f(t) d t \quad \text { and } m_{-1}=\int_{t_{0.1}}^{t_{0.8}} f(t) / t d t
$$

The theoretical and experimental partial time moments are linked by the two following relationships where $e$ is the specimen thickness:

$$
m_{0}=m_{0}^{*} \cdot e^{2} / a \text { and } m_{(-1)}=m_{(-1)}^{*}
$$

A relation between the theoretical moments $m_{0}^{*}$ and $m_{-1}^{*}$, named identification function $F$, is established by a polynomial fit of couples of values $\left(m_{0}^{*}, m_{-1}^{*}\right)$ calculated from thermograms obtained for various values of $B i$ using the analytical model. The coefficients $b_{i}$ depend on the geometrical ratio $R / e$ of the specimen (where $R$ is the radius of the specimen).

$$
m_{0}^{*}=F\left(m_{-1}^{*}\right)=\sum_{i=0}^{n} b_{i} \cdot\left(m_{-1}\right)^{i}
$$

Equation 5 gives as example the identification function $F$ determined by LNE in the case of a $3 \mathrm{~mm}$ thick specimen with a diameter of $10 \mathrm{~mm}$.

$$
F\left(m_{-1}\right)=-0.06767 \cdot m_{-1}+0.502198 \cdot m_{-1}^{2}-0.172615 \cdot m_{-1}^{3}
$$

The thermal diffusivity $a$ is then given by the following relationship by combining Eqs. 3 and 4:

$$
a=F\left(m_{-1}\right) \cdot e^{2} / m_{0}
$$




\section{Assessment of Measurement Uncertainties}

The analytical expression of the uncertainty associated to thermal diffusivity measurements performed with the new configuration of the laser flash apparatus of LNE is established in accordance with the ISO/BIPM Guide to the expression of uncertainty in measurement [13]. This uncertainty results from the combination of the standard uncertainties on the calculation of the partial time moments $u\left(m_{0}\right)$ and $u\left(m_{-1}\right)$, on the thickness determination $u(e)$, on the establishment of the identification function $u(F)$, on the measurement process $u(\bar{a})$ and $u_{\text {hyp }}(a)$, and on the measurement of the specimen temperature $u_{T}(a)$.

The analytical expression of the variance $u^{2}(a)$ is determined by applying the propagation law of variances to the mathematical model given by Eq. 6, assuming that the partial time moments $m_{0}$ and $m_{-1}$ are correlated together and are not dependent on the thickness $e$ and on the identification function coefficients $b_{i}$. The coefficients $b_{i}$ are assumed to be correlated together and not dependent on the thickness $e$.

$$
\begin{aligned}
u^{2}(a)= & c_{m_{0}}^{2} \cdot u^{2}\left(m_{0}\right)+c_{m_{-1}}^{2} \cdot u^{2}\left(m_{-1}\right)+2 \cdot c_{m_{0}} \cdot c_{m_{-1}} \cdot u\left(m_{0}, m_{-1}\right) \\
& +c_{e}^{2} \cdot u^{2}(e)+c_{F}^{2} \cdot u^{2}(F)+u^{2}(\bar{a})+u_{h y p}^{2}(a)+u_{T}^{2}(a)
\end{aligned}
$$

with $c_{e}=2 \cdot e \cdot \sum_{i=0}^{n} b_{i} \cdot m_{-1}^{i} / m_{0} \quad c_{F}=e^{2} / m_{0}$

$$
c_{m_{0}}=-e^{2} \cdot \sum_{i=0}^{n} b_{i} \cdot m_{-1}^{i} / m_{0}^{2} \quad c_{m_{-1}}=e^{2} \cdot \sum_{i=1}^{n} i \cdot b_{i} \cdot m_{-1}^{i-1} / m_{0}
$$

The evaluations of the terms of Eq. 7 are summarized in the following sections. More detailed can be found in [11], in particular regarding the assessment of the variance $u^{2}\left(m_{0}\right)$ and $u^{2}\left(m_{-1}\right)$, and covariance $u\left(m_{0}, m_{-1}\right)$ of the partial time moments $m_{0}$ and $m_{-1}$.

\subsection{Variances $u^{2}\left(m_{0}\right)$ and $u^{2}\left(m_{-1}\right)$ and Covariance $u\left(m_{0}, m_{-1}\right)$ of the Partial Time Moments}

The uncertainty associated with the partial time moments $m_{0}$ and $m_{-1}$ (calculated with Eq. 2) results from the combination of the uncertainties on the calculation of $f(t)$, on the measurement of the time $t$, on the determination of the limits of integration $t_{0.1}$ and $t_{0.8}$, and on the numerical integration method.

- The uncertainty on the normalized thermogram $f(t)$ (calculated with Eq. 1) results from the combination of the uncertainties on the measurement of the voltage $U(t)$ delivered by the IR detector, on the determination of the baseline $U_{0}$ and the maximum voltage $U_{\max }$, and on the uncertainty due to the assumption of linearity of the voltage $U(t)$ coming from the IR detector with the temperature $T$ of the rear face of the specimen. 
The uncertainty on the measurement of the voltage $U(t)$ is due to the noise, and to the resolution and calibration of the detection chain, these three factors being considered as not correlated. The uncertainty due to the assumption of linearity is considered to be not dependent on the other uncertainty factors affecting the calculation of the normalized thermogram. As three IR detectors are used depending on the investigated temperature ranges, the assessment of this uncertainty factor has been done as a function of temperature for each detector, the sensitivity being different from one detector to another.

- The uncertainty associated with the measurement of the time $t$ results from the combination of the uncertainties on acquisition time step $\Delta t$ and on the determination of the initial time $t_{0}$. The duration and the temporal profile of the laser pulse are both taken into account in the determination of the initial time $t_{0}$ by shifting the origin of time by a value corresponding to the chronological centroid of the laser pulse, according to the correction method proposed by Azumi [24]. The uncertainty on the time $t$ is actually equal to that on the initial time $t_{0}$, the uncertainty on $\Delta t$ being negligible.

The term of covariance $u\left(m_{0}, m_{-1}\right)$ is attributable to the fact that the same normalized thermogram $f(t)$ is used for the calculation of the partial time moments $m_{0}$ and $m_{-1}$. It is considered that the only significant covariance between $m_{0}$ and $m_{-1}$ is generated by the assumption of linearity of the detector response, the other uncertainty factors affecting the calculation of $m_{0}$ and $m_{-1}$ being independent.

\subsection{Variance of the Thickness $u^{2}(e)$}

The thickness $e_{0}$ of the specimen is measured at room temperature $R T$ (usually $23{ }^{\circ} \mathrm{C}$ ) using a calibrated micrometre. At the test temperature $T>R T$, the thickness $e$ of the specimen is equal to the thickness $e_{0}$ measured at $R T$ corrected by the thermal expansion of the specimen between these two temperatures. The uncertainty associated to the determination of the thickness $e$ results therefore from the combination of the uncertainties on the measurement of the thickness $e_{0}$ and on the calculation of the correction $\Delta_{e}$ due to thermal expansion performed according to Eq. 8 .

$$
\Delta_{e}=\alpha_{l} \cdot e_{0} \cdot(T-R T)
$$

- The uncertainty on the thickness $e_{0}$ results from the combination of the uncertainties due to the repeatability of measurements, and to the calibration and resolution of the micrometre, these three components being considered as independent.

- The uncertainty on the correction of the thickness results from the combination of the uncertainties on the determination of the mean coefficient of 
linear thermal expansion $\alpha_{l}$ and on the measurement of the room temperature, the temperature of test and the specimen thickness $e_{0}$.

\subsection{Variance of the Identification Function $u^{2}(F)$}

The variance of the identification function $F$, which is established by a polynomial fit of couples of values $\left(m_{0}^{*}, m_{-1}^{*}\right)$, is a combination of the variances of the coefficients $b_{i}$, the covariance between coefficients $b_{i}$ and the residual variance of the regression due to the error of the model.

\subsection{Variances Due to the Measurement Process $u^{2}(\bar{a})$ and $u_{h y p}^{2}(a)$}

LNE determines the thermal diffusivity of a material at a given temperature by performing three successive measurements on the same specimen under repeatability conditions, the result being equal to the average of these measurements. The corresponding uncertainty factor $u(\bar{a})$, which is partially due to the operator effect for the selection of $U_{0}$ and $U_{\max }$, is calculated from the repeatability of the three consecutive measurements.

Another uncertainty factor linked to the measurement process need to be assessed in addition.

All estimation techniques of thermal diffusivity based on the laser flash method assumed that the experimental conditions during the measurements are strictly identical to the hypotheses used to establish the theoretical model (cf. Sect. 2.2): Spatial uniformity of the energy deposited by the laser beam on the specimen front face, duration of the pulse negligible compared to the rear face temperature rise time, heat losses characterized by a uniform heat exchange coefficient.

The variance $u_{h y p}^{2}(a)$ due to the use of the function $F$ for experimental conditions different from the assumptions for which it was determined, has been estimated by modelling the heat transfer in $3 \mathrm{~mm}$ thick specimens. This has been performed for different initial and boundary conditions, by changing the laser pulse duration, the spatial profil (e.g., uniform or Gaussian) and diameter of the laser beam, the distribution of the heat-exchange coefficients on the specimen faces, and the diameter of the area sighted by the IR detector on the rear face of the specimen. The variance $u_{h y p}^{2}(a)$ is a combination of the standard uncertainties quantified for these four components, which are assumed to be not correlated.

\subsection{Variance $u_{T}^{2}(a)$ on the Thermal Diffusivity Due to the Variance on the Test Temperature $T$}

The specimen temperature $T$ is measured either thanks to a thermocouple fixed on the sample holder for measurements performed in the resistive furnace (for temperature from $23{ }^{\circ} \mathrm{C}$ to $800{ }^{\circ} \mathrm{C}$ ) or by using radiative thermometers for 
measurements performed in the inductive furnace (from $700{ }^{\circ} \mathrm{C}$ to $3000{ }^{\circ} \mathrm{C}$ ). The uncertainty associated to the measurement of $T$ results from the uncertainty linked to the resolution and calibration of the temperature measuring chains, and the uncertainty due to the stability and the homogeneity of the furnaces temperature, these four uncertainty factors being considered independent.

As thermal diffusivity is a temperature-dependent physical property, the uncertainty on the temperature $T$ has a contribution on the uncertainty associated to the thermal diffusivity measurement (even if temperature is not a parameter directly used in the determination of thermal diffusivity) via the relationship $a=G(T)$ giving the variation of thermal diffusivity versus temperature. The variance on the thermal diffusivity due to the variance on the test temperature $T$ is expressed by Eq. 9, the polynomial relationship $a=G(T)$ being determined for each tested material from the experimental results obtained in the investigated temperature range.

$$
u_{T}^{2}(a)=(\partial G(T) / \partial T)^{2} \cdot u^{2}(T)
$$

\section{Application to the Study of Three Refractory Materials}

The thermal diffusivity of three solid homogeneous refractory materials (pure molybdenum $99.9 \%$ and tungsten $99.95 \%$, and isotropic graphite IG210 from Toyo Tanso) has been measured with the new configuration of the LFA of LNE (cf. Section 2), and the associated uncertainties have been assessed according to the method described in the Sect. 3. These materials have been selected due to their high melting point $\left(2620{ }^{\circ} \mathrm{C}\right.$ for the molybdenum and $3420{ }^{\circ} \mathrm{C}$ for the tungsten $)$ or high sublimation temperature (more than $3650{ }^{\circ} \mathrm{C}$ for the graphite). The measurements have been performed from $23{ }^{\circ} \mathrm{C}$ to $2200{ }^{\circ} \mathrm{C}$ in case of molybdenum, up to $2400{ }^{\circ} \mathrm{C}$ for the tungsten and up to $3000{ }^{\circ} \mathrm{C}$ for the isotropic graphite.

The linear thermal expansion coefficient of the three studied materials was measured beforehand under inert atmosphere from $23{ }^{\circ} \mathrm{C}$ to $2000{ }^{\circ} \mathrm{C}$, during three successive cycles with heating and cooling rates of $5 \mathrm{~K} \cdot \mathrm{min}^{-1}$, with horizontally operating differential push rod dilatometer. The mean linear thermal expansion coefficient $\alpha_{l}$ between $T_{0}=23{ }^{\circ} \mathrm{C}$ and $T$ is given by Eq. 10, where $\Delta L$ is the expansion measured between $T_{0}$ and $T$, and $L_{T_{0}}$ is the length of the specimen at $T_{0}$. The data obtained are used for the measurements of thermal diffusivity at high temperature, in order to calculate the corrections on the specimen thickness due to thermal expansion.

$$
\alpha_{l}=\frac{1}{T-T_{0}} \cdot \frac{\Delta L}{L_{T_{0}}}
$$

The mean linear thermal expansion coefficients measured for the three materials by LNE are presented in Table 1 as a function of temperature. These values correspond to the average of the data obtained for the second and the third cycles. These materials exhibit indeed thermal expansion hysteresis for the first thermal cycle which could be explained by the relaxation of the residual stresses caused by the preparation (e.g., machining) of the specimens. 
Table 1 Mean thermal expansion coefficients of the isotropic graphite, tungsten and molybdenum

\begin{tabular}{|c|c|c|c|c|c|}
\hline \multicolumn{6}{|c|}{ Mean thermal expansion coefficient $\left(10^{-6} \mathrm{~K}^{-1}\right)$} \\
\hline \multirow[t]{2}{*}{ Temperature $\left({ }^{\circ} \mathrm{C}\right)$} & \multirow{2}{*}{$\begin{array}{l}\text { Isotropic } \\
\text { graphite }\end{array}$} & \multicolumn{2}{|c|}{ Tungsten } & \multicolumn{2}{|c|}{ Molybdenum } \\
\hline & & LNE & {$[25,26]$} & LNE & [27] \\
\hline 23 & - & - & - & - & - \\
\hline 50 & 4.05 & 4.45 & 4.45 & 5.06 & - \\
\hline 100 & 4.16 & 4.50 & 4.49 & 5.23 & - \\
\hline 150 & 4.27 & 4.55 & 4.53 & 5.35 & - \\
\hline 200 & 4.37 & 4.59 & 4.56 & 5.41 & - \\
\hline 250 & 4.48 & 4.63 & 4.58 & 5.45 & - \\
\hline 300 & 4.58 & 4.66 & 4.61 & 5.49 & - \\
\hline 400 & 4.77 & 4.72 & 4.65 & 5.54 & - \\
\hline 600 & 5.09 & 4.81 & 4.73 & 5.67 & - \\
\hline 800 & 5.34 & 4.89 & 4.81 & 5.79 & - \\
\hline 1000 & 5.51 & 4.98 & 4.89 & 5.94 & - \\
\hline 1200 & 5.65 & 5.08 & 4.97 & 6.15 & 6.20 \\
\hline 1400 & 5.78 & 5.20 & 5.07 & 6.40 & 6.40 \\
\hline 1600 & 5.96 & 5.34 & 5.17 & 6.65 & 6.64 \\
\hline 1800 & 6.21 & 5.52 & 5.29 & 7.07 & 6.90 \\
\hline 2000 & 6.56 & 5.75 & 5.42 & 7.45 & 7.21 \\
\hline
\end{tabular}

The maximum operating temperature of the dilatometer being $2000{ }^{\circ} \mathrm{C}$, the mean coefficient of thermal expansion measured between $23{ }^{\circ} \mathrm{C}$ and $2000{ }^{\circ} \mathrm{C}$ is used to correct the thickness specimens for thermal diffusivity measurements performed above $2000{ }^{\circ} \mathrm{C}$. The expanded uncertainty (coverage factor $k=2$ ) on thermal expansion coefficients of isotropic graphite, tungsten and molybdenum is estimated to be $10 \%$. The results are in good agreement with data obtained by absolute measurement methods based on interferometric techniques [25-27], the difference between LNE's results and published values being within the expanded uncertainty estimated by LNE.

Tables 2, 3, and 4 present the thermal diffusivity values obtained by LNE (for $3 \mathrm{~mm}$ thick specimens), respectively, for isotropic graphite IG210, tungsten and molybdenum as a function of temperature, as well as the associated expanded uncertainties $(k=2)$. These thermal diffusivity values correspond to the average of three measurements repeated at each temperature level. The data in normal font refer to raw values of thermal diffusivity while the data in italic are corrected values that take into account the thermal expansion (given in Table 1) of the tested materials. Figures 3, 4, and 5 plot the corrected values of thermal diffusivity (without uncertainty bars for more readability) obtained for the three materials versus temperature.

Tables 5, 6, and 7 give three examples of uncertainty budget evaluated in the case of the measurement of thermal diffusivity of the isotropic graphite IG210 at $1000{ }^{\circ} \mathrm{C}, 2000{ }^{\circ} \mathrm{C}$ and $3000{ }^{\circ} \mathrm{C}$, with detail of the different uncertainty components described in Sect. 3. 
Table 2 Thermal diffusivity of isotropic graphite IG210 and associated uncertainty

\begin{tabular}{llll}
\hline Temperature $\left({ }^{\circ} \mathrm{C}\right)$ & $\begin{array}{l}\text { Thermal diffusivity } \\
\left(10^{-6} \mathrm{~m}^{2} \cdot \mathrm{s}^{-1}\right)\end{array}$ & $\begin{array}{l}\text { Expanded } \\
\text { Uncertainty } \\
(k=2)\end{array}$ \\
\cline { 2 - 3 } & Raw data & Corrected value & $(\%)$ \\
\hline 23 & 87.91 & 87.91 & 3.2 \\
50 & 78.38 & 78.40 & 3.2 \\
100 & 64.83 & 64.87 & 3.1 \\
149 & 55.22 & 55.28 & 3.1 \\
199 & 47.33 & 47.40 & 3.1 \\
249 & 41.42 & 41.50 & 3.0 \\
300 & 36.88 & 36.97 & 3.0 \\
400 & 30.05 & 30.16 & 3.0 \\
601 & 22.35 & 22.48 & 3.0 \\
806 & 18.27 & 18.42 & 3.1 \\
1001 & 15.60 & 15.77 & 3.1 \\
1198 & 13.71 & 13.89 & 3.3 \\
1400 & 12.27 & 12.47 & 3.4 \\
1601 & 11.18 & 11.39 & 3.7 \\
1799 & 10.31 & 10.54 & 3.7 \\
2001 & 9.54 & 9.79 & 3.8 \\
2201 & 8.98 & 9.24 & 4.0 \\
2398 & 8.46 & 8.73 & 4.2 \\
2600 & 8.08 & 8.36 & 4.3 \\
2796 & 7.77 & 8.06 & 4.4 \\
2985 & 7.33 & 7.62 & 4.7 \\
\hline & & &
\end{tabular}

The relative expanded uncertainty $u(a)$ associated to thermal diffusivity measurements performed by the laser flash method, which corresponds to two standard deviations $(k=2)$, is estimated to be between $3 \%$ and $5 \%$ for the three materials in the temperature range from $23{ }^{\circ} \mathrm{C}$ to $3000{ }^{\circ} \mathrm{C}$.

It is maximal at the ends of the temperature range investigated here ( $c f$. Tables 2 , 3 , and 4) and reaches a minimum between $300{ }^{\circ} \mathrm{C}$ and $600{ }^{\circ} \mathrm{C}$. This is mainly due to the uncertainty components on the measurement of the IR detectors output voltage which vary in opposite ways when the temperature increases. The uncertainty due to the assumption of linearity of this voltage with the temperature, which is a preponderant component of the uncertainty $u\left(m_{-1}\right)$ at low temperature, decreases with increasing temperature until becoming negligible at $1400{ }^{\circ} \mathrm{C}$. Conversely, signal to noise ratio which decreases when the temperature increases leads to a higher uncertainty on the determination the partial time moments $m_{0}$ and $m_{-1}$ and to a worse repeatability of the three successive measurements at high temperature.

The Tables 5, 6, and 7 show that the main uncertainty components on thermal diffusivity measurement are those related to the calculation of the partial time moment $m_{-1}$ and to the hypotheses used to establish the theoretical model. The contribution 
Table 3 Thermal diffusivity of tungsten and associated uncertainty

\begin{tabular}{llll}
\hline Temperature $\left({ }^{\circ} \mathrm{C}\right)$ & $\begin{array}{l}\text { Thermal diffusivity } \\
\left(10^{-6} \mathrm{~m}^{2} \cdot \mathrm{s}^{-1}\right)\end{array}$ & $\begin{array}{l}\text { Expanded } \\
\text { uncertainty } \\
(k=2)\end{array}$ \\
\cline { 2 - 3 } & Raw data & Corrected value & $(\%)$ \\
\hline 23 & 68.61 & 68.61 & 3.5 \\
51 & 65.65 & 65.67 & 3.5 \\
100 & 62.72 & 62.76 & 3.4 \\
149 & 59.92 & 59.99 & 3.4 \\
199 & 57.44 & 57.53 & 3.4 \\
250 & 54.88 & 55.00 & 3.3 \\
301 & 52.55 & 52.69 & 3.2 \\
401 & 49.12 & 49.30 & 3.2 \\
601 & 44.12 & 44.37 & 3.3 \\
802 & 40.63 & 40.94 & 3.5 \\
991 & 38.18 & 38.55 & 3.7 \\
1197 & 36.53 & 36.97 & 3.7 \\
1397 & 34.74 & 35.24 & 3.8 \\
1598 & 32.70 & 33.25 & 3.9 \\
1799 & 30.90 & 31.51 & 4.0 \\
1996 & 28.86 & 29.52 & 4.2 \\
2195 & 26.87 & 27.55 & 4.6 \\
2402 & 25.28 & 25.98 & 5.0 \\
\hline
\end{tabular}

of the first one increases when temperature goes from $1000{ }^{\circ} \mathrm{C}$ to $3000{ }^{\circ} \mathrm{C}$ (cf. above explanations) while the relative weight of the second one in the uncertainty budgets decreases. This uncertainty associated with the theoretical assumptions is equal to about $1 \%$ of the thermal diffusivity whatever the temperature and the material.

The relative contribution of the uncertainty due to test temperature measurement is relatively low up to $800{ }^{\circ} \mathrm{C}$ (less than $2 \%$ of the total variance) when performing the thermal diffusivity measurements in the resistive furnace. It is between $3.2 \%$ and $7.1 \%$ if the measurements are performed from $1000{ }^{\circ} \mathrm{C}$ to $3000{ }^{\circ} \mathrm{C}$ with the inductive furnace. The standard uncertainty $(k=1)$ associated with the measurement of the test temperature increases strongly from about $1{ }^{\circ} \mathrm{C}$ at $800{ }^{\circ} \mathrm{C}$ (with the resistive furnace) to $5.4{ }^{\circ} \mathrm{C}$ at $1000{ }^{\circ} \mathrm{C}$ and more than $15^{\circ} \mathrm{C}$ at $3000{ }^{\circ} \mathrm{C}$ (with the inductive furnace), due to the uncertainties associated with the homogeneity and calibration of the inductive furnace, despite the in situ calibration procedure applied. Although the uncertainty in measuring the specimen temperature increases with temperature, its relative contribution remains less or equal to $7.1 \%$ (cf. Tables 5, 6, 7) for all specimens in the whole temperature range, owing to weak temperature dependence of thermal diffusivity at elevated temperatures. The shape of the curve presented in Fig. 3 confirms that the thermal diffusivity of the isotropic graphite IG210 is less sensitive to temperature when the temperature increases (this behaviour is similar for tungsten and molybdenum). 
Table 4 Thermal diffusivity of molybdenum and associated uncertainty

\begin{tabular}{llll}
\hline Temperature $\left({ }^{\circ} \mathrm{C}\right)$ & $\begin{array}{l}\text { Thermal diffusivity } \\
\left(10^{-6} \mathrm{~m}^{2} \cdot \mathrm{s}^{-1}\right)\end{array}$ & $\begin{array}{l}\text { Expanded } \\
\text { uncertainty } \\
(k=2) \\
\end{array}$ & Raw data \\
\cline { 2 - 4 } & Corrected value & \\
\hline 23 & 55.22 & 55.22 & 3.5 \\
50 & 53.87 & 53.88 & 3.5 \\
101 & 51.55 & 51.59 & 3.4 \\
151 & 49.37 & 49.44 & 3.4 \\
201 & 47.74 & 47.83 & 3.4 \\
251 & 46.40 & 46.52 & 3.3 \\
301 & 45.19 & 45.33 & 3.2 \\
402 & 42.89 & 43.07 & 3.2 \\
600 & 39.74 & 40.00 & 3.3 \\
800 & 36.97 & 37.30 & 3.5 \\
1000 & 34.55 & 34.95 & 3.7 \\
1205 & 32.15 & 32.62 & 3.7 \\
1400 & 29.29 & 29.81 & 3.8 \\
1599 & 26.65 & 27.21 & 3.9 \\
1799 & 24.29 & 24.90 & 4.0 \\
1999 & 22.34 & 23.00 & 4.2 \\
2201 & 20.12 & 20.78 & 4.7 \\
\hline & & &
\end{tabular}

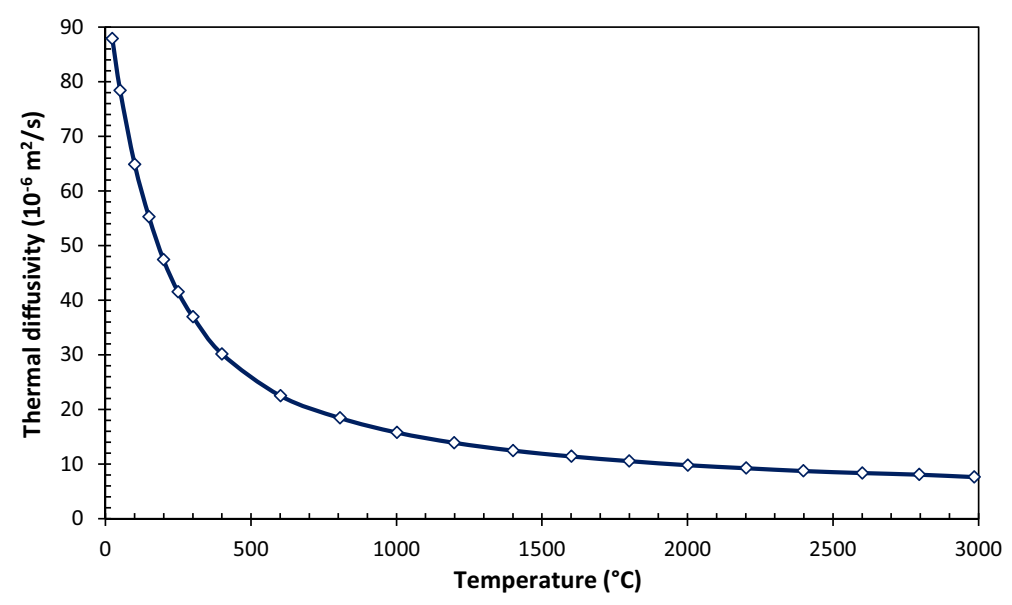

Fig. 3 Thermal diffusivity of the isotropic graphite IG210 measured by LNE from $23{ }^{\circ} \mathrm{C}$ to $3000{ }^{\circ} \mathrm{C}$

As the thermal expansion of materials is here taken into account when determining the thickness of the specimen for diffusivity measurements carried out above $23{ }^{\circ} \mathrm{C}$, then the associated uncertainty term has a relative contribution limited to about $1 \%$ of the overall variance whatever the temperature and material. If the thermal expansion 


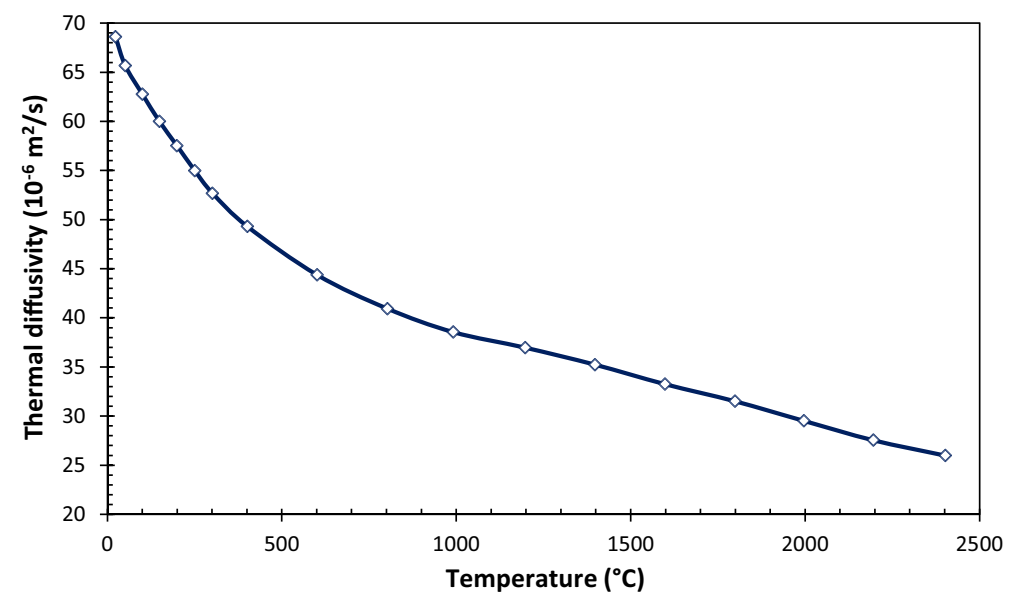

Fig. 4 Thermal diffusivity of the tungsten measured by LNE from $23^{\circ} \mathrm{C}$ to $2400{ }^{\circ} \mathrm{C}$

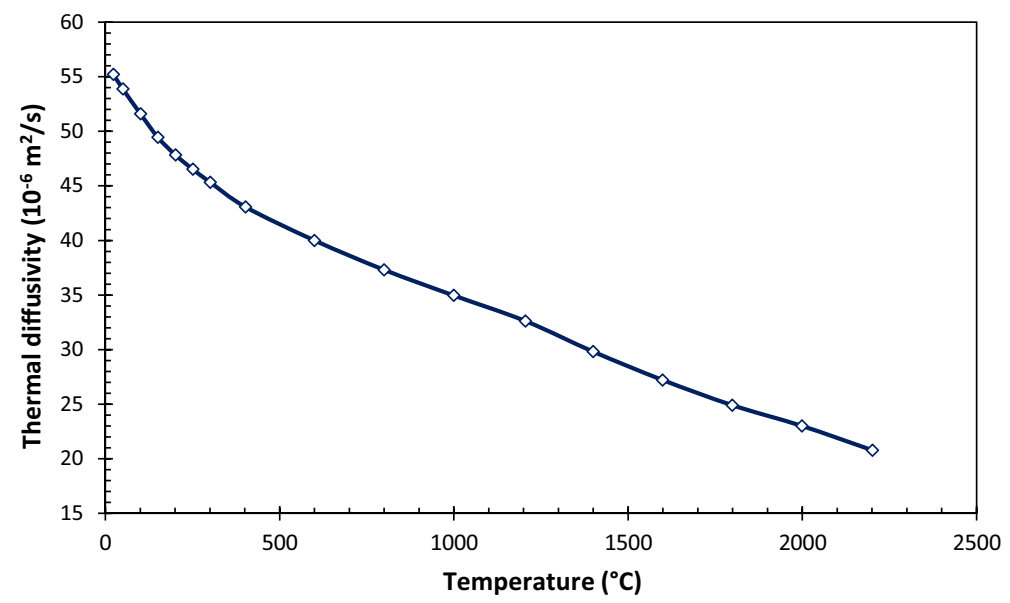

Fig. 5 Thermal diffusivity of the molybdenum measured by LNE from $23^{\circ} \mathrm{C}$ to $2200{ }^{\circ} \mathrm{C}$

of the specimen is not considered, then the thickness used in the calculation of the thermal diffusivity for all test temperatures is the one measured at room temperature. This results in an underestimation of the measured thermal diffusivity values which can reach here up to $2.7 \%, 3.2 \%$ and $3.8 \%$, respectively, in the case of tungsten at 
Table 5 Uncertainty budget associated with thermal diffusivity value measured at $1000{ }^{\circ} \mathrm{C}$

\begin{tabular}{|c|c|c|c|c|}
\hline $\begin{array}{l}\text { Uncertainty com- } \\
\text { ponent }\end{array}$ & Value & $\begin{array}{l}\text { Standard uncertainty } \\
(k=1) \text { or covariance }\end{array}$ & $\begin{array}{l}\text { Sensitivity coef- } \\
\text { ficient }\end{array}$ & Contribution $^{\mathrm{a}}$ \\
\hline$X_{i}$ & $x_{i}$ & $u\left(x_{i}\right)$ or $u\left(x_{i}, x_{j}\right)$ & $\partial a / \partial X_{i}$ & $(\%)$ \\
\hline $\begin{array}{l}\text { Partial time moment } \\
\mathrm{m}_{-1}\end{array}$ & 0.4944 & $1.86 \times 10^{-3}$ & $6.94 \times 10^{-5} \mathrm{~m}^{2} \cdot \mathrm{s}^{-1}$ & 27.8 \\
\hline $\begin{array}{l}\text { Partial time moment } \\
\mathrm{m}_{0}\end{array}$ & $0.0396 \mathrm{~s}$ & $1.47 \times 10^{-4} \mathrm{~s}$ & $-3.97 \times 10^{-4} \mathrm{~m}^{2} \cdot \mathrm{s}^{-2}$ & 5.7 \\
\hline $\begin{array}{l}\text { Covariance factor } \\
\mathrm{u}\left(\mathrm{m}_{0}, \mathrm{~m}_{-1}\right)\end{array}$ & 0 & $2.77 \times 10^{-9} \mathrm{~s}$ & $-5.51 \times 10^{-8} \mathrm{~m}^{4} \cdot \mathrm{s}^{-3}$ & -0.3 \\
\hline Thickness e & $3.013 \times 10^{-3} \mathrm{~m}$ & $2.34 \times 10^{-6} \mathrm{~m}$ & $1.04 \times 10^{-2} \mathrm{~m} \cdot \mathrm{s}^{-1}$ & 1.0 \\
\hline $\begin{array}{l}\text { Identification func- } \\
\text { tion F }\end{array}$ & 0.06844 & $2.24 \times 10^{-4}$ & $2.30 \times 10^{-4} \mathrm{~m}^{2} \cdot \mathrm{s}^{-1}$ & 4.4 \\
\hline $\begin{array}{l}\text { Theoretical assump- } \\
\text { tions }\end{array}$ & 0 & $1.78 \times 10^{-7} \mathrm{~m}^{2} \cdot \mathrm{s}^{-1}$ & 1 & 52.9 \\
\hline $\begin{array}{l}\text { Average of } 3 \text { meas- } \\
\text { urements }\end{array}$ & $15.77 \times 10^{-6} \mathrm{~m}^{2} \cdot \mathrm{s}^{-1}$ & $4.04 \times 10^{-8} \mathrm{~m}^{2} \cdot \mathrm{s}^{-1}$ & 1 & 2.7 \\
\hline $\begin{array}{l}\text { Specimen tempera- } \\
\text { ture } \mathrm{T}\end{array}$ & $1001{ }^{\circ} \mathrm{C}$ & $5.40^{\circ} \mathrm{C}$ & $\begin{array}{l}1.10 \times 10^{-8} \\
\mathrm{~m}^{2} \cdot \mathrm{s}^{-1} \cdot{ }^{\circ} \mathrm{C}^{-1}\end{array}$ & 5.8 \\
\hline Thermal diffusivity a & \multicolumn{2}{|c|}{ Standard uncertainty } & \multicolumn{2}{|c|}{ Expanded uncertainty $(k=2)$} \\
\hline $15.70 \times 10^{-6} \mathrm{~m}^{2} \cdot \mathrm{s}^{-1}$ & \multicolumn{2}{|c|}{$2.45 \times 10^{-7} \mathrm{~m}^{2} \cdot \mathrm{s}^{-1}$} & $4.91 \times 10^{-7} \mathrm{~m}^{2} \cdot \mathrm{s}^{-1}$ & $3.1 \%$ \\
\hline
\end{tabular}

${ }^{a}$ The values expressed in \% correspond to the contributions of each uncertainty component in terms of variance with respect to the total variance on the thermal diffusivity $a$

Table 6 Uncertainty budget associated with thermal diffusivity value measured at $2000{ }^{\circ} \mathrm{C}$

\begin{tabular}{|c|c|c|c|c|}
\hline $\begin{array}{l}\text { Uncertainty compo- } \\
\text { nent }\end{array}$ & Value & $\begin{array}{l}\text { Standard uncertainty } \\
(k=1) \text { or covariance }\end{array}$ & Sensitivity coefficient & Contribution \\
\hline$X_{i}$ & $x_{i}$ & $u\left(x_{i}\right)$ or $u\left(x_{i}, x_{j}\right)$ & $\partial a / \partial X_{i}$ & $(\%)$ \\
\hline $\begin{array}{l}\text { Partial time moment } \\
\mathrm{m}_{-1}\end{array}$ & 0.4595 & $2.59 \times 10^{-3}$ & $4.88 \times 10^{-5} \mathrm{~m}^{2} \cdot \mathrm{s}^{-1}$ & 44.8 \\
\hline $\begin{array}{l}\text { Partial time moment } \\
\mathrm{m}_{0}\end{array}$ & $0.0537 \mathrm{~s}$ & $2.44 \times 10^{-4} \mathrm{~s}$ & $-1.86 \times 10^{-4} \mathrm{~m}^{2} \cdot \mathrm{s}^{-2}$ & 5.7 \\
\hline $\begin{array}{l}\text { Covariance factor } \\
\mathrm{u}\left(\mathrm{m}_{0}, \mathrm{~m}_{-1}\right)\end{array}$ & 0 & $5.30 \times 10^{-9} \mathrm{~s}$ & $-1.82 \times 10^{-8} \mathrm{~m}^{4} \cdot \mathrm{s}^{-3}$ & -0.3 \\
\hline Thickness e & $3.036 \times 10^{-3} \mathrm{~m}$ & $2.94 \times 10^{-6} \mathrm{~m}$ & $6.58 \times 10^{-3} \mathrm{~m} \cdot \mathrm{s}^{-1}$ & 1.1 \\
\hline $\begin{array}{l}\text { Identification func- } \\
\text { tion F }\end{array}$ & 0.05819 & $2.25 \times 10^{-4}$ & $1.72 \times 10^{-4} \mathrm{~m}^{2} \cdot \mathrm{s}^{-1}$ & 4.2 \\
\hline $\begin{array}{l}\text { Theoretical assump- } \\
\text { tions }\end{array}$ & 0 & $1.15 \times 10^{-7} \mathrm{~m}^{2} \cdot \mathrm{s}^{-1}$ & 1 & 37.0 \\
\hline $\begin{array}{l}\text { Average of } 3 \text { measure- } \\
\text { ments }\end{array}$ & $9.79 \times 10^{-6} \mathrm{~m}^{2} \cdot \mathrm{s}^{-1}$ & $3.87 \times 10^{-8} \mathrm{~m}^{2} \cdot \mathrm{s}^{-1}$ & 1 & 4.2 \\
\hline $\begin{array}{l}\text { Specimen tempera- } \\
\text { ture } \mathrm{T}\end{array}$ & $2001{ }^{\circ} \mathrm{C}$ & $10.1^{\circ} \mathrm{C}$ & $\begin{array}{l}3.35 \times 10^{-9} \\
\mathrm{~m}^{2} \cdot \mathrm{s}^{-1} \cdot{ }^{\circ} \mathrm{C}^{-1}\end{array}$ & 3.2 \\
\hline Thermal diffusivity $a$ & \multicolumn{2}{|c|}{ Standard uncertainty } & \multicolumn{2}{|c|}{ Expanded uncertainty $(k=2)$} \\
\hline $9.99 \times 10^{-6} \mathrm{~m}^{2} \cdot \mathrm{s}^{-1}$ & \multicolumn{2}{|c|}{$1.89 \times 10^{-7} \mathrm{~m}^{2} \cdot \mathrm{s}^{-1}$} & $3.78 \times 10^{-7} \mathrm{~m}^{2} \cdot \mathrm{s}^{-1}$ & $3.8 \%$ \\
\hline
\end{tabular}


Table 7 Uncertainty budget associated with thermal diffusivity value measured at $3000{ }^{\circ} \mathrm{C}$

\begin{tabular}{|c|c|c|c|c|}
\hline $\begin{array}{l}\text { Uncertainty compo- } \\
\text { nent }\end{array}$ & Value & $\begin{array}{l}\text { Standard uncertainty } \\
(k=1) \text { or covariance }\end{array}$ & Sensitivity coefficient & Contribution \\
\hline$X_{i}$ & $x_{i}$ & $u\left(x_{i}\right)$ or $u\left(x_{i}, x_{j}\right)$ & $\partial a / \partial X_{i}$ & $(\%)$ \\
\hline $\begin{array}{l}\text { Partial time moment } \\
\mathrm{m}_{-1}\end{array}$ & 0.3975 & $3.05 \times 10^{-3}$ & $4.61 \times 10^{-5} \mathrm{~m}^{2} \cdot \mathrm{s}^{-1}$ & 61.2 \\
\hline $\begin{array}{l}\text { Partial time moment } \\
\mathrm{m}_{0}\end{array}$ & $0.0506 \mathrm{~s}$ & $3.40 \times 10^{-4} \mathrm{~s}$ & $-1.52 \times 10^{-4} \mathrm{~m}^{2} \cdot \mathrm{s}^{-2}$ & 8.3 \\
\hline $\begin{array}{l}\text { Covariance factor } \\
\mathrm{u}\left(\mathrm{m}_{0}, \mathrm{~m}_{-1}\right)\end{array}$ & 0 & $2.43 \times 10^{-9} \mathrm{~s}$ & $-1.40 \times 10^{-8} \mathrm{~m}^{4} \cdot \mathrm{s}^{-3}$ & -0.1 \\
\hline Thickness e & $3.055 \times 10^{-3} \mathrm{~m}$ & $3.67 \times 10^{-6} \mathrm{~m}$ & $5.02 \times 10^{-3} \mathrm{~m} \cdot \mathrm{s}^{-1}$ & 1.1 \\
\hline $\begin{array}{l}\text { Identification func- } \\
\text { tion F }\end{array}$ & 0.04161 & $2.24 \times 10^{-4}$ & $1.84 \times 10^{-4} \mathrm{~m}^{2} \cdot \mathrm{s}^{-1}$ & 5.3 \\
\hline $\begin{array}{l}\text { Theoretical assump- } \\
\text { tions }\end{array}$ & 0 & $5.81 \times 10^{-8} \mathrm{~m}^{2} \cdot \mathrm{s}^{-1}$ & 1 & 10.5 \\
\hline $\begin{array}{l}\text { Average of } 3 \text { measure- } \\
\text { ments }\end{array}$ & $7.62 \times 10^{-6} \mathrm{~m}^{2} \cdot \mathrm{s}^{-1}$ & $4.62 \times 10^{-8} \mathrm{~m}^{2} \cdot \mathrm{s}^{-1}$ & 1 & 6.6 \\
\hline $\begin{array}{l}\text { Specimen tempera- } \\
\text { ture } \mathrm{T}\end{array}$ & $2985^{\circ} \mathrm{C}$ & $15.2^{\circ} \mathrm{C}$ & $\begin{array}{l}3.14 \times 10^{-9} \\
\mathrm{~m}^{2} \cdot \mathrm{s}^{-1} \cdot{ }^{\circ} \mathrm{C}^{-1}\end{array}$ & 7.1 \\
\hline Thermal diffusivity a & \multicolumn{2}{|c|}{ Standard uncertainty } & \multicolumn{2}{|c|}{ Expanded uncertainty $(k=2)$} \\
\hline $7.67 \times 10^{-6} \mathrm{~m}^{2} \cdot \mathrm{s}^{-1}$ & \multicolumn{2}{|c|}{$1.79 \times 10^{-7} \mathrm{~m}^{2} \cdot \mathrm{s}^{-1}$} & $3.58 \times 10^{-7} \mathrm{~m}^{2} \cdot \mathrm{s}^{-1}$ & $4.7 \%$ \\
\hline
\end{tabular}

$2402{ }^{\circ} \mathrm{C}$, molybdenum at $2201{ }^{\circ} \mathrm{C}$ and graphite at $2985{ }^{\circ} \mathrm{C}$ (cf. Tables 2, 3, 4). The order of magnitude of these errors being the same as that of the expanded uncertainty for the temperatures above $1000{ }^{\circ} \mathrm{C}$, it is therefore essential to apply a thermal expansion correction in the determination of the specimen thickness used for high temperature thermal diffusivity measurements by the laser flash method.

\section{Conclusions}

The assessment of the uncertainties associated with high temperature thermal diffusivity measurements by the laser flash method is described in detail in this paper for the first time. These uncertainties were calculated taking into account the different sources of uncertainty, such as the measurement method, the calibration and measurement means, the environmental conditions, etc. The influence parameters were identified and quantified and the analytical expression of measurement uncertainty was established. Thermal diffusivity values measured on isotropic graphite, tungsten and molybdenum in the temperature range from $23^{\circ} \mathrm{C}$ to $3000{ }^{\circ} \mathrm{C}$, with a laser flash apparatus adapted at LNE, are presented with their corresponding expanded uncertainty $(k=2)$. The expanded relative uncertainty associated with the thermal diffusivity determination is estimated to be between $3 \%$ and $5 \%$ for the three refractory materials, if the thermal expansion of the tested specimens is corrected. Uncertainty budgets presented for the isotropic graphite at $1000{ }^{\circ} \mathrm{C}, 2000{ }^{\circ} \mathrm{C}$ and $3000{ }^{\circ} \mathrm{C}$ show 
that the main uncertainty components are those related to the analysis of the experimental curve, in particular due to the noise on the IR signal, and to some bias in the application of the laser flash method itself where the initial and boundary conditions are not exactly the same for the theoretical model and for the experiment.

Acknowledgments This project 17IND11 Hi-TRACE has received funding from the EMPIR programme co-financed by the Participating States and from the European Union's Horizon 2020 research and innovation programme.

Open Access This article is licensed under a Creative Commons Attribution 4.0 International License, which permits use, sharing, adaptation, distribution and reproduction in any medium or format, as long as you give appropriate credit to the original author(s) and the source, provide a link to the Creative Commons licence, and indicate if changes were made. The images or other third party material in this article are included in the article's Creative Commons licence, unless indicated otherwise in a credit line to the material. If material is not included in the article's Creative Commons licence and your intended use is not permitted by statutory regulation or exceeds the permitted use, you will need to obtain permission directly from the copyright holder. To view a copy of this licence, visit http://creativecommons.org/licen ses/by/4.0/.

\section{References}

1. Y. Katoh, L. Snead, J. Nucl. Mater. 526, 151849 (2019). https://doi.org/10.1016/j.jnucmat.2019.151849

2. Wings in Orbit: Scientific and Engineering Legacies of the Space Shuttle, 1971-2010, chap. Thermal protection systems, 182-199, NASA, ISBN 978-0160868467 (2011)

3. L. Hallstadius, S. Johnson, E. Lahoda, Prog Nucl Energy 57, 71 (2012). https://doi.org/10.1016/j.pnucene. 2011.10.008

4. Z. Duan, H. Yang, Y. Satoh, K. Murakami, S. Kano, Z. Zhao, J. Shen, H. Abe, Nucl. Eng. Des. 316, 131 (2017). https://doi.org/10.1016/j.nucengdes.2017.02.031

5. R. Monti, M. De Stefano Fumo, R. Savino, J. Thermophys. Heat Transf. 20, 500 (2006). https://doi.org/10. 2514/1.17947

6. E. Boulier, G. Pinaud, P. Bugnon, Thermal issues related to Exomars EDLS performance, in Proceeding of 28th European Space Thermal Analysis Workshop, ESA/ESTEC, Noordwijk, The Netherlands, Oct. $14^{\text {th }}-15$ th $2014,117-126$, European Space Agency - ISSN 1022-6656 (2014)

7. F. Buffenoir, T. Pichon, R. Barreteau, Thermal protection system post-flight preliminary analysis, in 7 th European Conference for Aeronautics and Space Science, Milan (2017). https://doi.org/10.13009/ EUCASS2017-330

8. K. Boboridis, B. Hay, ATW-Int. J. Nucl. Power 65, 140 (2020)

9. T. Baba, A. Ono, Meas. Sci. Technol. 12, 2046 (2001). https://doi.org/10.1088/0957-0233/12/12/304

10. L. Vozár, W. Hohenauer, Int. J. Thermophys. 26, 1899 (2005). https://doi.org/10.1007/ s10765-005-8604-5

11. B. Hay, J.-R. Filtz, J. Hameury, L. Rongione, Int. J. Thermophys. 26, 1883 (2005). https://doi.org/10. 1007/s10765-005-8603-6

12. F.L. Migliorini, E.H.C. Silva, P.A. Grossi, R. A.N. Ferreira, D.M. Camarano, Calculated uncertainty of the thermal diffusivity measurement based on flash laser method, in XIX IMEKO World Congress, Fundamental and Applied Metrology, September 6-11, 2009, Lisbon, Portugal

13. JCGM 100:2008 (GUM 1995 with minor corrections) - Evaluation of measurement data - Guide to the expression of uncertainty in measurement (2008)

14. I. Pencea, I. Plotog, M. Branzei, A. Bibis, P. Svasta, Proceedings of the 36th International Spring Seminar on Electronics Technology, 195 (2013). https://doi.org/10.1109/ISSE.2013.6648241

15. A. Allard, N. Fischer, G. Ebrard, B. Hay, P. Harris, L. Wright, D. Rochais, J. Mattout, Metrologia 53, S1-S9 (2016). https://doi.org/10.1088/0026-1394/53/1/S1

16. A. Lunev, R. Heymer, Rev. Sci. Instrum. 91, 064902 (2020). https://doi.org/10.1063/1.5132786

17. B. Hay, J. Hameury, J.-R. Filtz, F. Haloua, R. Morice, High Temp-High Press 39, 181 (2010)

18. W.J. Parker, R.J. Jenkins, G.L. Abbott, J. Appl. Phys. 32, 1679 (1961). https://doi.org/10.1063/1.17284 17 
19. A. Degiovanni, M. Laurent, Rev. Phys. Appl. 21, 229 (1986). https://doi.org/10.1051/rphysap:01986 002103022900

20. B. Hay, L. Rongione, J.-R. Filtz, J. Hameury, High Temp-High Press 37, 13 (2008)

21. M. Akoshima, B. Hay, J. Zhang, L. Chapman, T. Baba, The international pilot comparison on thermal diffusivity measurement using the laser flash method, Thermal Conductivity 30, 367, ISBN 978-160595-015-0 (2010)

22. M. Akoshima, B. Hay, J. Zhang, L. Chapman, T. Baba, Int. J. Thermophys. 34, 763 (2013). https://doi. org/10.1007/s10765-012-1209-X

23. G. Failleau, N. Fleurence, O. Beaumont, R. Razouk, J. Hameury, B. Hay, High Temp-High Press 50, 149 (2021). https://doi.org/10.32908/hthp.v50.1013

24. T. Azumi, Y. Takahashi, Rev. Sci. Instrum. 52, 1411 (1981). https://doi.org/10.1063/1.1136793

25. R. Kirby, T. Hahn, Certificate of Standard Reference Material 737. Tungsten - thermal expansion, National Bureau of Standards, Washington (1976)

26. A.P. Miiller, A. Cezairliyan, Int. J. Thermophys. 11, 619 (1990). https://doi.org/10.1007/BF01184332

27. A.P. Miiller, A. Cezairliyan, Int. J. Thermophys. 6, 695 (1985). https://doi.org/10.1007/BF00500340

Publisher's Note Springer Nature remains neutral with regard to jurisdictional claims in published maps and institutional affiliations. 